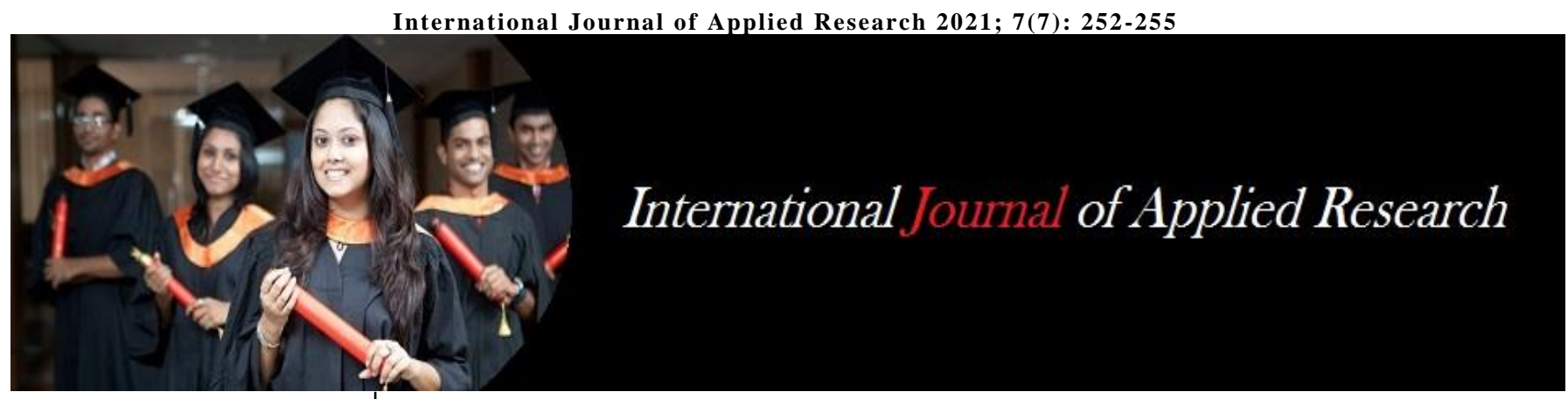

ISSN Print: 2394-7500 ISSN Online: 2394-5869 Impact Factor: 8.4 IJAR 2021; 7(7): 252-255 www.allresearchjournal.com Received: 10-05-2021 Accepted: 12-06-2021

\section{Dharvinder Singh} Lecturer, Department of Psychology, University of Jammu, Jammu and Kashmir, India

\section{Karuna Gupta}

Lecturer, Department of Psychology, University of Jammu, Jammu and Kashmir, India
Corresponding Author: Dharvinder Singh Lecturer, Department of Psychology, University of Jammu, Jammu and Kashmir, India

\section{Spiritual intelligence and mindfulness as predictors of life satisfaction among youth of Jammu and Kashmir}

\section{Dharvinder Singh and Karuna Gupta}

DOI: https://doi.org/10.22271/allresearch.2021.v7.i7d.8772

Abstract

This study investigated the relationship among spiritual intelligence mindfulness and life satisfaction among young adults. The sample consisted of 168 young adults. Spiritual Intelligence Questionnaire (SIQ) by Abdollahzadeh et al. (2009) ${ }^{[1]}$ Mindful Attention Awareness Scale (MASS) by Brown and Ryan (2003) ${ }^{[7]}$ Satisfaction with Life Scale (SWLS) by Diener et al., (1985) ${ }^{[12]}$ were used to study the variables. Pearson product moment correlation and stepwise regression were applied to analyze the data. Results indicated that there was significant positive relationship among spiritual intelligence mindfulness and life satisfaction whereas only spiritual intelligence significantly predicted life satisfaction among young adults.

Keywords: spiritual intelligence, mindfulness, life satisfaction, young adults

\section{Introduction}

Spirituality is the individual search for understanding answers to ultimate questions regarding life, about meaning, and about relationship to the sacred or transcendent, which may (or may not) lead to or arise from the development of religious rituals and the formation of the community (Koenig, McCullough, \& Larson, 2001) ${ }^{[18]}$. Emmons (2000) ${ }^{[13]}$ defines spiritual intelligence as "the adaptive use of spiritual information to facilitate day to day problem solving and goal attainment".

Spiritual Intelligence is the intelligence with which we access our deepest meanings, purposes, and highest motivations (Zohar, 2000) ${ }^{[29]}$. Nasel (2004) ${ }^{[21]}$ defines spiritual intelligence as the application of spiritual abilities and resources to practical contexts. People use spiritual intelligence when they draw on their spiritual abilities and resources to make meaningful decisions, deliberate over existential issues, or attempt problem solving in daily life.

"Mindfulness means paying attention in a particular way on purpose, in the present moment, and nonjudgmentally." (Kabat-Zinn, 1994) ${ }^{[15]}$. Mindfulness is remembering to pay attention to our present moment experience (Shapiro \& Carlson, 2009; Black, 2011) ${ }^{[24,6]}$.

Mindfulness is a mind-body practice that has been considered to benefit both psychological as well as physical health. The main psychological change that occurs during practice of mindfulness is an increased awareness of thoughts, feelings, and sensations in the present moment. With time practice of mindfulness can help us to become aware of the space between noticing experiences and reacting to them by letting us slow down and observe the processes of our mind (Black, 2010) ${ }^{[5]}$. It is a flexible state of mind - an openness to novelty, a process of actively drawing novel distinctions. When we are mindful, we become sensitive to context and perspective and we are situated in the present (Snyder \& Lopez, 2002) ${ }^{[26]}$. Mindfulness is an active search for novelty, whereas mindlessness involves passively zoning out to everyday life (Snyder \& Lopez, 2007) ${ }^{[27]}$.

Subjective well-being is a multidimensional construct which consists of positive affect, negative affect and global judgments of life satisfaction (Diener et al., 1999) ${ }^{[11]}$. Life satisfaction is therefore a part of subjective well-being. Life satisfaction commonly denotes a judgmental process in which individuals holistically evaluate the condition of their lives based on their own distinct and unique set of criteria (Pavot \& Deiner, 2008) ${ }^{[22]}$. 
Life satisfaction is a concept that can also be defined as how an individual evaluates his/her life as being positive in accordance with his/her own criteria, it is also a cognitive and judgmental process (Diener, Emmons, Larsen \& Griffin, 1985) [12]. Life satisfaction as a global assessment of person's quality of life by his own according to his or her own settled criteria of success (Shin and Johnson, 1978) ${ }^{[25]}$. Life satisfaction is an outcome achieved by people comparing what they have and want to have. (Altay \& Avci, 2009) ${ }^{[2]}$.

The role of spiritual intelligence in predicting quality of life among 143 students of Quechan University was investigated by Bolghani-Abadi, Ghofrani and Abde-Khodaei (2012) ${ }^{[9]}$ and concluded that spiritual intelligence significantly predicting the quality of life. Whereas Koohbanani, Dastjerdi, Vahidi and Far (2013) ${ }^{[16]}$ stated that there was no significant relationship between spiritual intelligence and life satisfaction among gifted female high school students.

Sahebalzamani et al. (2013) [23] conducted a study to examine the relationship between spiritual intelligence, psychological well-being and purpose in life. A sample of 270 nurses from some hospitals of Tehran University was taken and the results showed a significant relationship between spiritual intelligence with psychological well-being and having a purpose in life.

Kong, Wang and Zhao (2014) ${ }^{[19]}$ examined mindfulness and life satisfaction among 310 Chinese adults and found that there was a significant positive relationship between mindfulness and life satisfaction and mindfulness significantly predicted life satisfaction.

Another study by Bajaj and Pande (2016) ${ }^{[8]}$ found that mindfulness predicted life satisfaction among 327 undergraduate university students in India.

A recent study suggested that there was a significant relationship between spiritual intelligence and life satisfaction among gifted students (Alghraibeh \& Alotaibi, 2017) ${ }^{[3]}$. Ari et al., (2020) ${ }^{[4]}$ stated that there was a significant positive relationship between mindfulness and life satisfaction among 379 university students from Gazi University. Hejazi et al., (2020) ${ }^{[14]}$ showed a significant relationship between spiritual intelligence and life satisfaction among nursing students. Cheung and Lau (2021) [10] found a significant positive relationship between mindfulness and life satisfaction among 133 Chinese mindfulness practitioners.

On the basis of review of literature following hypotheses were formed.

H1 There will be a significant relationship between spiritual intelligence and life satisfaction among young adults.
H2 There will be a significant relationship between mindfulness and life satisfaction among young adults.

H3 Spiritual intelligence and mindfulness are the significant predictors of life satisfaction among young adults.

\section{Method \\ Sample}

The sample of the present study consisted of 168 young adults of Jammu and Kashmir Purposive sampling technique was used for the selection of the sample.

\section{Measures}

Spiritual Intelligence Questionnaire (SIQ) by Abdollahzadeh et al. (2009) ${ }^{[1]}$. It is a 5-point scale with 29 items, where each statement has five alternatives ranging from completely agree to disagree completely. Responses are summed up to obtain the total score. There are no reverse items. The scores range from 29-145 and higher scores are associated with a higher level of Spiritual Intelligence.

Mindful Attention Awareness Scale (MASS) by Brown and Ryan (2003) ${ }^{[7]}$. It is a 6-point scale with 15 items where each statement has six alternatives ranging from almost always to almost never. The total score is obtained by summing up all the items. There are no reverse items. The scores range from 15-90 and higher scores are indicative of a higher level of mindfulness.

Satisfaction with Life Scale (SWLS) by Diener et al., (1985) [12]. This scale consists of 5 items with a 7-point scale from 1(totally disagree) to 7 (totally agree). Higher scores indicated greater life satisfaction.

\section{Data Analysis}

Data was analyzed using IBM SPSS statistics version 20. Pearson product moment correlation was used to investigate the association between spiritual intelligence, mindfulness and life satisfaction among young adults. Stepwise regression analyses were used to explore the role of spiritual intelligence and mindfulness as predictors of life satisfaction of young adults.

\section{Results and Discussion}

Table 1: Showing mean and standard deviation among spiritual intelligence, mindfulness and life satisfaction $(n=168)$

\begin{tabular}{|c|c|c|}
\hline Variables & Mean & Standard deviation \\
\hline Spiritual intelligence & 62.05 & 14.18 \\
\hline Mindfulness & 58.28 & 11.61 \\
\hline Life satisfaction & 23.52 & 2.77 \\
\hline
\end{tabular}

Table 2: Relationship between spiritual intelligence, mindfulness and life satisfaction among young adults. (N=168)

\begin{tabular}{|c|c|c|c|}
\hline & Spiritual intelligence & Mindfulness & Life satisfaction \\
\hline Spiritual Intelligence & 1 & $0.196^{* *}$ & $0.552^{* *}$ \\
\hline Mindfulness & - & 1 & $0.205^{* *}$ \\
\hline Life satisfaction & - & - & 1 \\
\hline \multirow{2}{*}{} & - &
\end{tabular}

**Significant at 0.01 level, *Significant at 0.05 level

The present study aimed to examine the relationship between spiritual intelligence, mindfulness and life satisfaction of young adults and to explore the understanding of spiritual intelligence and mindfulness as predictors of life satisfaction among young adults. Table 1 represents the mean score and standard deviations on spiritual intelligence, mindfulness and life satisfaction.
Table 2 shows the positive and significant relationship between Spiritual Intelligence and mindfulness at 0.05 level $(r=0.196)$ on the other hand relationship between spiritual intelligence and life satisfaction were also found to be significant and positive at 0.01 level $(\mathrm{r}=0.552 * *)$. In case of Mindfulness and life satisfaction a positive and significant association was found at 0.01 level $\left(\mathrm{r}=0.205^{* *}\right)$. 
Thus, our hypothesis stating that there will be a significant relationship between spiritual intelligence, mindfulness and life satisfaction among young adults is accepted.

The results indicate that higher the levels of spiritual intelligence and mindfulness, higher will be the life satisfaction in young adults. The present results are consistent with the findings of Yuan, Xiang and Chen (2021) who also found a significant relationship between mindfulness and life satisfaction among 1021 college students. Kumawat and Puri (2019) ${ }^{[20]}$ also found a significant relationship between spiritual intelligence and life satisfaction among youth.

Table 3: Stepwise regression for the criterion variable life satisfaction as predicted by spiritual intelligence and mindfulness.

\begin{tabular}{|c|c|c|c|c|c|c|c|}
\hline Model & Predictor & $\mathbf{R}$ & R square & $\mathbf{R}^{2}$ change & Beta & F & Sig \\
\hline 1. & Spiritual intelligence & .552 & .305 & .301 & .552 & 72.80 & .000 \\
\hline
\end{tabular}

Another hypothesis was whether spiritual intelligence and mindfulness could predict life satisfaction among young adults. It was found that spiritual intelligence alone accounted for 30.5 per cent unique variance in life satisfaction whereas mindfulness was excluded from the model itself. It was inferred that out of spiritual intelligence and mindfulness only spiritual intelligence predict the life satisfaction among young adults. Hypothesis 2 is also accepted. These findings corroborated the findings of previous study that showed that spiritual intelligence significantly predicted life satisfaction (Kalantarkousheh, Nickamal, Amanollahi \& Dehghani, 2014) ${ }^{[17]}$.

\section{Conclusion}

Findings of the present study throw light on the association between spiritual intelligence, mindfulness and life satisfaction among young adults and reflected a positive and significant association. Another finding showed that Spiritual intelligence was the significant predictor of life satisfaction among young adults. The present finding suggested that levels of mindfulness can be enhanced through mindfulness-based interventions which ultimately increase the life satisfaction of the individuals. Spiritual intelligence helps the individuals to solve daily life problems through their spirituality and to take benefit from situations and interactions with others. It gives them the capability to give and to express forgiveness, appreciation, contemplation, faithfulness acceptance, compassion, as well as tolerance. These all virtues boost the life satisfaction of the people. The present study has certain limitations which need to be discussed. The sample size of the present study was relatively small. Therefore, the findings may vary for a large sample. The participants were the young adults of Jammu and Kashmir therefore one can generalize results to the population of other young adults cautiously. Only young adults were taken in the study, middle aged and old aged people can also be taken in future researches.

\section{References}

1. Abdollahzadeh $\mathrm{H}$, Baqherpour $\mathrm{M}$, Bozhmehrani $\mathrm{S}$, Lotfi M. Spiritual Intelligence: Concepts, Measurements and its Applications. Ravansanji Publications 2009.

2. Altay B, Avci IA. The relation between the self-care strength and life satisfaction of the elderly living in a nursing home. Dicle Medical Journal 2009;36(4):9.

3. Alghraibeh AM, Alotaibi AM. Spiritual Intelligence and Its Correlation with Life Satisfaction among Gifted Students. Journal of Education and Practice 2017, 8(36).

4. Ari C, Ulun C, Yarayan YE, Dursun M, Bozkurt TM, Üstün UD. Mindfulness, healthy life skills and life satisfaction in athletes and university students. Progress in Nutrition 2020. 22. 10.23751/pn.v22i2-S.10561

5. Black DS. A 40-year publishing history of mindfulness. Mindfulness Research Monthly 2010, 1(5). Retrieved from http://www.mindfulexperience.org

6. Black DS. A brief definition of mindfulness. Mindfulness Research Guide 2011. Retrieved from http://www.mindfulexperience.org.

7. Brown KW, Ryan RM. The benefits of being present: Mindfulness and its role in psychological wellbeing. Journal of Personality and Social Psychology 2003;84(4):822-848. https://doi.org/10.1037/00223514.84.4.822.

8. Bajaj B, Pande N. Mediating role of resilience in the impact of mindfulness on life satisfaction and affect as indices of subjective well-being. Personality and Individual Differences 2016;93:63-67.

9. Bolghan-Abadi M, Ghofrani F, Abde-Khodaei MS. Study of the spiritual intelligence role in predicting university students' quality of life. Journal of religion and health 2012;53(1):79-85. https://doi.org/10.1007/s10943-012-9602-0.

10. Cheung R, Lau EN. Is Mindfulness Linked to Life Satisfaction? Testing Savoring Positive Experiences and Gratitude as Mediators. Frontiers in psychology 2021;12:591103. https://doi.org/10.3389/fpsyg.2021.591103

11. Diener E, Suh E, Lucas R, Smith H. Subjective wellbeing: three decades of progress. Psychological Bulletin 1999;125:276-302. 10.1037/0033-2909.125.2.276.

12. Diener E, Emmons RA, Larsen RJ, Griffin S. The Satisfaction with Life Scale. Journal of Personality Assessment 1985;49:71-75.

13. Emmons RA. Is spirituality an intelligence? The International Journal for the Psychology of Religion 2000;10:27-34.

14. Hejazi F, Rahimi M, Jahromi MK, Shafiei H, Yeganeh S, Tayebeh Bahmani T. The Relationship between Spiritual Intelligence and Happiness in Nursing Students studying at Shiraz and Tehran Universities of Medical Science. European Journal of Molecular \& Clinical Medicine 2020, 07(02).

15. Kabat-Zinn J. Wherever you go there you are: Mindfulness meditation in everyday life. Hyperion Books 1994.

16. Koohbanani SE, Dastjerdi R, Vahidi T, Far MG. The Relationship between Spiritual Intelligence and emotional intelligence with life satisfaction among birjand gifted female high school students. Procedia Social and Behavioral Sciences 2013;84,(9):314-320.

17. Kalantarkousheh SM, Nickamal N, Amanollahi Z, Dehghani E. Spiritual Intelligence and Life Satisfaction 
among Married and Unmarried Females. Open Journal of Social Sciences 2014;2:172-177.

18. Koenig HG, McCullough M, Larson DB. Handbook of religion and health. Oxford University Press 2001.

19. Kong F, Wang X, Zhao J. Dispositional mindfulness and life satisfaction: The role of core self-evaluations. Personality and Individual Differences 2014;56:165169.

20. Kumawat NS, Puri PA. Relationship between Spiritual Intelligence and Life Satisfaction among Youth. International Journal of Indian Psychology 2019; 7(1):986-989. 10.25215/0701.112.

21. Nasel DD. Spiritual orientation in relation to spiritual intelligence: A consideration of traditional Christianity and New Age/individualistic spirituality. Unpublished doctoral dissertation. University of South Australia 2004.

22. Pavot W, Diener E. The satisfaction with life scale and emerging construct of life satisfaction. Journal of Positive Psychology 2008;3(2):137-152. Doi:10.1080/17439760701756946

23. Sahebalzamani M, Farahani H, Abasi R, Talebi M. The relationship between spiritual intelligence with psychological well-being and purpose in life of nurses. Iranian journal of nursing and midwifery research 2013;18(1):38-41.

24. Shapiro SL, Carlson LE. The art and science of mindfulness: Integrating mindfulness into psychology and the helping professions. APA 2009.

25. Shin DC, Johnson DM. Avowed happiness as an overall assessment of the quality of life. Social Indicators Research 1978;5:475-492. 10.1007/BF00352944

26. Snyder C, Lopez S. Handbook of Positive Psychology. Oxford University Press 2002.

27. Snyder C, Lopez S. Positive Psychology: The Scientific and Practical Explorations of Human Strengths. Sage Publications 2007.

28. Yuan Z, Xiang Y, Chen Z. Mindfulness Associates Life Satisfaction: The Mediating Role of Internal Control and the Presence of Meaning in Life. International Journal of Mental Health Promotion 2020, 23(1).

29. Zohar D. SQ: Connecting with Our Spiritual Intelligence. Bloomsbury 2000. 